\title{
LIDERANÇA HUMANIZADA E SEUS IMPACTOS POSITIVOS NA PRODUTIVIDADE
}

\section{HUMANIZED LEADERSHIP AND ITS POSITIVE IMPACTS ON PRODUCTIVITY}

\author{
Luan Tabolka da Silva - luantabolkasilva@outlook.com \\ Fabrício Domingues Antônio - fabricio.antonio@fatectq.edu.br \\ Faculdade de Tecnologia de Taquaritinga (Fatec) - Taquaritinga - São Paulo - Brasil
}

DOI: 10.31510/infa.v17i1.799

\section{RESUMO}

O objetivo principal deste estudo é evidenciar o processo de liderança, assim como os tipos de líderes existentes, e ressaltar como o líder desenvolve seu papel de forma humanizada pode contribuir para motivar seus colaboradores e como consequência gerar impactos positivos na produtividade. Os líderes são grandes responsáveis pelo processo de motivação dentro das empresas, a qual somente cresce sob o trabalho de seus funcionários. Empresas de sucesso são categóricas em mostrar a influência que a motivação e o trabalho do líder, exercem sobre seus colaboradores. A metodologia utilizada neste estudo foi de revisão de literatura. Todo o contexto estudado mostra a importância que o líder exerce sobre os colaboradores, impactando a vida dos mesmos dentro da empresa de forma positiva ou negativa. É notório que quando o líder trabalha de forma humanizada as consequências são as maiores e melhores possíveis, trazendo para os colaboradores motivação, confiança, aceitação e outros fatores que somam para o desenvolvimento organizacional.

Palavras-chave: Humanização. Liderança. Produtividade.

\begin{abstract}
The main objective of this study is to highlight the leadership process, as well as the types of existing leaders, and to highlight how the leader who develops his role in a humanized way can contribute to motivate his employees and, as a consequence, generate positive impacts on productivity. Leaders are largely responsible for the motivation process within companies, which only grows under the work of their employees. Successful companies are categorical in showing the influence that the leader's motivation and work have on their employees. The methodology used in this study was a literature review. The entire context studied shows the importance that the leader has on employees, impacting their lives within the company in a positive or negative way. It is well known that when the leader works in a humanized way, the consequences are the greatest and best possible, bringing motivation, confidence, acceptance and other factors that add up to organizational development for employees.
\end{abstract}


Keywords: Humanization. Leadership. Productivity.

\section{INTRODUÇÃO}

A concorrência entre as organizações aumentou a partir da evolução e do grande mercado consumidor. A fidelização dos clientes tornou-se essencial para obtenção de sucesso e permanência no mercado.

Chiavenato (2011) ressalta que a globalização trouxe consigo a necessidade de alta produção como forma de atender um mercado cada vez maior e mais exigente. Com o tempo, o autor ressalta que o processo de globalização começa a ser entendido, e define que as organizações dentro dessa nova realidade passam a entender que produzir em grande quantidade não era o aspecto fundamental, era necessário produzir com qualidade, como forma de garantir satisfação ao mercado consumidor.

Segundo Duluc (2000) as organizações passam a entender que muito além da necessidade da qualidade do produto, estava a necessidade de qualificar o processo de produção, era necessário investir em seus colaboradores, pois quando os mesmos estavam satisfeitos contribuíam diretamente para o desenvolvimento da organização.

Chiavenato (2006) ressalta que a competência humana aliada a outros recursos organizacionais, dá origem à competência organizacional. Dentro deste contexto a gestão de pessoas dentro das organizações se faz necessária e deveria ser realizada por quem entendesse de tal processo. O gestor de pessoas deveria ter a capacidade de liderá-los, sempre relacionando as necessidades dos colaboradores com as necessidades das organizações, de forma a garantir a satisfação de ambos. Frente a essa realidade surge a figura do líder, como ideias e posturas diferentes do conhecido chefe.

Borges (2009) explica que em uma época envolta pelas grandes mudanças tecnológicas, a liderança se torna cada vez mais necessária nas organizações que buscam atingir os objetivos de estabilidade e permanência no mercado tão competitivo.

O objetivo deste trabalho é mostrar a importância da liderança humanizada como motivadora para o aumento da produtividade.

A justificativa para este estudo se deve ao fato da grande importância que o capital humano apresenta para o desenvolvimento das organizações. Investir em uma liderança mais humanizada traz grande influência para a vida empresarial dos colaboradores, os quais motivados e valorizados trabalham com maior eficiência. 
$\mathrm{O}$ artigo é disposto em seções e subseções. As seções trazem em seu contexto a definição de liderança, os tipos de líderes, a definição de liderança humanizada, e como os líderes envolvidos em motivar seus colaboradores podem aumentar a produtividade das empresas.

\section{REVISÃO DE LITERATURA}

Antes desse entender a função do líder, é importante evidenciar aspectos que definem $\mathrm{o}$ ato de liderar.

\subsection{Liderança}

De acordo com Nogueira (2005) no surgimento das indústrias, o capital humano não era valorizado, e as pessoas eram tratadas como objetos, cuja finalidade era o trabalho excessivo e a produção de lucros. A sociedade evoluiu e com ela o pensamento a respeito da importância do capital humano dentro das organizações. Visto a importância do capital humano para o desenvolvimento organizacional, as empresas têm buscado investir integralmente em todo o seu capital humano, e as pessoas passaram a ser vistas como a parte fundamental para o sucesso organizacional.

Chiavenato (2011) destaca que desde o início da Revolução Industrial havia mesmo que precariamente, a necessidade de se administrar as pessoas, uma vez que as mesmas eram essenciais para o desenvolvimento de todos os processos da indústria. Na verdade, era a máquina humana que fazia a máquina estrutural trabalhar.

Segundo Macêdo (2009) o patrimônio mais importante de uma empresa, são as pessoas que dela fazem parte, e sob essa perspectiva investir para que essas pessoas mudem e se sintam realmente inseridas dentro do processo empresarial tem sido um assunto de grande discussão. As mudanças são fundamentais para que as pessoas e organizações não permaneçam estáticas diante de um cenário de profundas transformações.

Chiavenato (2011) destaca que:

As organizações são verdadeiros seres vivos. Quando elas são bem-sucedidas, tendem a crescer ou, no mínimo, a sobreviver. O crescimento acarreta maior complexidade dos recursos necessários às suas operações, com o aumento de capital, incremento de tecnologia, atividades de apoio etc. E, de lambuja, provoca o aumento 
do número de pessoas, bem como a necessidade de intensificar a aplicação de seus conhecimentos, habilidades e destrezas indispensáveis à manutenção e competitividade do negócio. Tudo isso para se assegurar que os recursos materiais, financeiros e tecnológicos sejam utilizados com eficiência e eficácia (CHIAVENATO, 2011, p. 4).

Foi dentro do conceito de preocupação com o capital humano e a valorização do mesmo, que surge a figura do líder. Foi no fim dos anos 1980 que a figura do líder começou a ter espaço nas empresas, fator motivado pelo surgimento de uma concorrência desenfreada, que exigia funcionários mais motivados e dedicados. Dentro dessa realidade citaremos no tópico posterior o conceito de líder (CONSORTI, et al., 2011).

De acordo com Borges (2009) o ato de liderar, existe mesmo, antes da existência de sua definição concreta. Ao longo do processo evolucional da sociedade, diversas definições de liderança começaram a surgir. A "liderança é um fenômeno tipicamente social e ocorre exclusivamente em grupos sociais e nas organizações”. É um tipo de influência. De acordo com o autor a influência é uma forma psicológica e envolve conceitos como poder e autoridade, abrangendo as maneiras pelas quais as mudanças podem ser introduzidas no comportamento das pessoas e no grupo de pessoas (CHIAVENATO, 2006, p. 448).

Sobre o conceito de liderança Maximiano (2007) define:

Liderança é o processo de conduzir as ações ou influenciar o comportamento e a
mentalidade de outras pessoas. Proximidade física ou temporal não é importante no
processo. Um cientista pode ser influenciado por um colega de produção que nunca
viu ou mesmo que viveu em outra época. Líderes religiosos são capazes de
influenciar adeptos que estão muitos longes e que têm pouquíssima chance de vê-los
pessoalmente (MAXIMIANO, 2007, p. 277).

Nogueira (2005) ressalta que o sucesso das empresas, dependem das pessoas que produzem seus bens, qualquer que sejam eles. Sendo assim a valorização e a compreensão humana proporcionam melhor entrosamento e participação de seus colaboradores.

\subsection{Características do Líder}

Os líderes causam um profundo impacto na vida das pessoas nas organizações e destaca que a liderança não deve ser vista como sinônimo de administração. De acordo com o autor, "o administrador é responsável pelos recursos organizacionais e por funções como, planejar, organizar, dirigir e controlar a ação organizacional no sentido de alcançar objetivos". Já o líder pode atuar em grupos formais e informais e nem sempre é um administrador. 
(CHIAVENATO, 2006, p. 446).

"O líder torna as ideias tangíveis em reais. Não importa quão maravilhosa seja a visão, o líder eficiente deve usar uma metáfora, uma palavra ou um modelo para tornar tal visão clara para os outros" (BENNIS; SLATER, 2002, p. 13).

Hunter (2004) define líder da seguinte forma:

\begin{abstract}
Líder, chefe, comandante, autoridade, são algumas das primeiras palavras que nos ocorrem quando pensamos em liderança. É comum, também, sermos tentados a entender que liderar é tarefa aquelas pessoas com QI elevado, mais autoconfiantes ou bastante ambiciosas, ou ainda aquelas que têm sutis habilidades sociais. Contudo, observa-se que atualmente o conceito de liderança é colocado da seguinte forma: "Liderança representa a sua capacidade de influenciar pessoas a agir" (HUNTER, 2004, p. 105).
\end{abstract}

Segundo Baggio et al. (2007, p. 2) o papel do líder nesta nova sociedade deve ter como objetivo levar orientação, motivação. $O$ autor explica que não se deve confundir liderança com chefia, e define algumas diferenças de postura entre chefe e líder. São elas: o chefe conduz, o líder aconselha; o chefe inspira medo, o líder entusiasmo; o chefe diz "EU", o líder diz "NÓS"; o chefe se preocupa com as coisas, o líder com as pessoas; o chefe enxerga o hoje, o líder contempla o amanhã.

De acordo com a American management Association (2000, p. 111) alguns são os fatores que definem verdadeiramente um líder, e são esses: um bom líder depende tanto de seus seguidores como de si próprio; um bom líder sempre explica o motivo pelo qual atribui uma tarefa ou faz algum pedido a um funcionário; um bom líder é sempre capaz de delegar até mesmo tarefas importantes para seus funcionários; um bom líder não precisa ter seu estilo de liderança rígido. A flexibilidade é essencial à liderança eficaz; um bom líder sempre quer promover seus subordinados, mesmo correndo o risco de perdê-los; um bom líder inclui seus subordinados no processo de decisão.

O líder que desempenha um trabalho humanizado dentro das organizações, assume um importante papel frente aos colaboradores, é capaz de mudar comportamentos e a realidade de trabalho da empresa através de toda a motivação que ele traz aos colaboradores.

Dentro dessa realidade de entender o processo de liderança e a postura do líder, é importante entender os tipos de liderança. 


\subsection{Estilos de Liderança}

Segundo Chiavenato (2011, p. 308) "a liderança pode ser estudada em termos de estilos de comportamento do líder em relação a seus subordinados, isto é, modos como o líder orienta a sua conduta". Conforme o autor a liderança pode ser definida em três estilos: autocrática, democrática e liberal.

\subsubsection{Liderança Autocrática}

Segundo Macedo (2009, p. 41) o estilo autocrático é o mais antigo. Sua origem remonta da pré-história, quando os primeiros agrupamentos urbanos se uniram e surgiram os chefes. Nesse estilo, o líder determina as ideias e o que será feito pelo grupo, todos devem obedecê-lo, caso contrário seriam punidos severamente.

Ainda de acordo com o autor o uso da liderança autocrática, pode ser eficiente, dependendo da situação e do tipo de pessoa a ser liderada.

O líder autocrático é mais conhecido como "chefe". Seria aquele condutor que define o que e como deve ser feito. Podemos supor que se é ele quem define tudo, este acredita ser a sua opinião sempre a mais correta e ainda serem seus subordinados pouco merecedores de confiança. Fica nítido que a atenção principal deste líder está voltada para as tarefas e não para as relações humanas de seu grupo. Baseia seu poder geralmente na posição (cargo) que ocupa (CHIAVENATO, 2006, p. 324).

Chiavenato (2011) traz em seus estudos a experiência de dois autores que decidiram agrupar meninos e submetê-los durante seis semanas aos líderes que utilizavam os três estilos de Liderança. O autor destaca que os meninos submetidos a Liderança Autocrática mostraram um comportamento envolvido por tensão, frustração e agressividade, além disso o grupo não demonstrou nenhuma espontaneidade, nem iniciativa e nem formação de grupos de amizade.

Segundo Chiavenato (2011) o trabalho só se desenvolvia com a presença física do líder, quando o líder não estava presente, as atividades cessavam e os grupos expressavam sentimentos reprimidos de indisciplina e agressividade. 


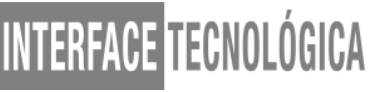

\subsubsection{Liderança Democrática}

Macedo (2009) ressalta que na liderança democrática as decisões são tomadas de forma conjunta com o líder, sobre quais as tarefas e a melhor forma de executá-las. O autor destaca que inserir todos no processo da tomada de decisões, não torna menos importante o papel do líder e afirma que esse estilo de liderança é recomendado em grupos de trabalho onde os integrantes sentem- se parte indispensável para o sucesso de todos e são capazes de contribuir na tomada de decisões.

Chiavenato (2011) ressalta que na liderança democrática o líder é atuante, consultivo e orientador. $\mathrm{O}$ autor destaca que o grupo submetido ao estilo democrático conseguiu desenvolver amizade e cordialidade.

Líder e subordinados passaram segundo Chiavenato (2011, p. 308) a desenvolver comunicações francas e cordiais, "o trabalho mostro um ritmo suave e seguro, mesmo quando o líder se ausentava. Houve um nítido sentido de responsabilidade e de comprometimento pessoal”.

\subsubsection{Liderança Liberal}

Segundo Macedo (2009, p. 43) na liderança liberal, o grupo decide sozinho sem a intervenção do líder, quais as tarefas e as formas de executá-la. Há liberdade total para as decisões grupais sem a participação do líder, ou com sua mínima participação.

Segundo Chiavenato (2011) no estilo de liderança liberal, o líder deixa todos a vontade. A respeito da pesquisa citada pelo autor, o mesmo deixa claro que nesse estilo embora as atividades do grupo tenham acontecido de forma intensa, a produção foi medíocre.

Chiavenato (2011) destaca que as tarefas foram desenvolvidas ao acaso, com muitas oscilações, e destaca que muito tempo foi perdido com discussões pessoais ao invés de discussões a respeito do trabalho. $\mathrm{O}$ autor destaca que nesse estilo de liderança foi possível perceber um individualismo agressivo e pouco respeito em relação ao líder. 


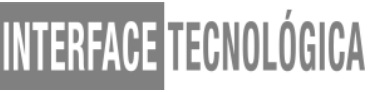

\subsection{Liderança Humanizada e seus Impactos na Produtividade}

O líder tem importante e amplo papel para motivar os colaboradores a desenvolver um importante trabalho dentro das empresas.

De acordo com Wunderlich (2017) os líderes humanizados são pessoas altamente motivadas, que gostam das pessoas e das atividades laborais que desenvolvem. O líder com visão humanizada entende que qualquer pessoa pode ser talentosa no seu contexto de entendimento e experiência. A motivação gerada pela liderança humanizada além de trazer importantes e satisfatórios resultados para a organização, está sempre à procura de melhoria contínua, a qual se dá por meio de conhecimentos e aperfeiçoamentos.

Dentro das empresas a motivação tem sido um aspecto muito importante. Motivar o colaborador tornou-se um fator de grande importância, quando se percebeu a necessidade de tratar cada colaborar de forma individual, verificando seus anseios e capacidades, fazendo do dele peça fundamental para o desenvolvimento das organizações. Essa motivação surgiu, relacionada a figura do líder, uma vez que um dos papéis fundamentais da liderança é motivar a equipe na qual o líder está inserido, garantindo bons resultados as organizações (CHIAVENATO, 2011).

De acordo com Drucker (2003, p. 45), o sucesso dos empreendimentos dependerá 99\% da capacidade de liderança e apenas $1 \%$ de todo o resto que é ensinado nas escolas tradicionais. "O papel da liderança é descobrir e desenvolver novos talentos e, muitas vezes, isso significa confrontar antigos conceitos".

Segundo Chiavenato (2011) uma das características dos líderes, é motivar e gerenciar o trabalho em equipe. De acordo com o autor o líder deve estar capacitado em construir equipes de trabalhos e fazê-las trabalhar com gradativos e maiores níveis de excelência. Ohmae (2006) afirma que a liderança não deve ser atribuída a qualquer um, sendo uma característica do líder integridade pessoal, e para o autor a integridade tem custo, o que muitas vezes é insuportável para as pessoas "comuns". O autor afirma que os chefes são comuns, já os líderes são raros.

Macedo (2009) afirma que o verdadeiro líder tem um papel de influenciador das pessoas, além de estimular o relacionamento entre as mesmas e o trabalho em equipe. Segundo o autor, um líder de sucesso não sabe apenas administrar os recursos da empresa, 
sabe reconhecer antes de tudo a individualidade de cada pessoa e dessa forma extrai o máximo de cada uma, aumentando a eficiência do grupo e da organização como um todo.

Wunderlich (2017) ressalta que as pessoas respeitas e motivadas não ficam estagnadas. Desenvolver a liderança humanizada tem sido o foco das organizações que valorizam o capital humano e sua eficiência.

\section{METODOLOGIA}

Boccatto (2006) define que a pesquisa bibliográfica tem como objetivo a busca pela resolução de um problema através de revisão de literatura de materiais já publicados, analisando e discutindo as diversas contribuições científicas.

O trabalho é constituído por revisão de literatura. O método utilizado para o desenvolvimento deste artigo foi pesquisa bibliográfica, onde foram consultados livros, artigos, teses, monografias revistas, documentos apresentados em simpósios e congressos e sites da internet.

\section{RESULTADOS E DISCUSSÃO}

O Quadro 1 traz os resultados de alguns trabalhos encontrados que responderam os objetivos do trabalho, ao evidenciarem a importância da liderança como aspecto motivador para o aumento da produtividade.

Quadro 1: Principais resultados encontrados

\begin{tabular}{|c|c|c|c|}
\hline Título & Autor(es) & Objetivo & Resultados \\
\hline $\begin{array}{l}\text { Liderança e sua } \\
\text { importância para } \\
\text { Motivação } \\
\text { Organizacional. }\end{array}$ & $\begin{array}{l}\text { ALVES, T. O.; } \\
\text { ESTENDER, } \\
\text { A.C. }\end{array}$ & $\begin{array}{lr}\text { Analisar } & \mathrm{a} \\
\text { importância } & \text { da } \\
\text { liderança } & \text { para } \\
\text { motivação } & \text { dos } \\
\text { colaboradores. } & \end{array}$ & $\begin{array}{l}\text { As empresas trabalham } \\
\text { competências e características } \\
\text { de líderes que variam a } \\
\text { utilização de acordo com o } \\
\text { momento vivido da entidade, é } \\
\text { necessário trabalhar diferentes } \\
\text { situações organizacionais. }\end{array}$ \\
\hline $\begin{array}{l}\text { Importância da } \\
\text { liderança como } \\
\text { fator } \\
\text { Motivacional } \\
\text { dentro das }\end{array}$ & $\begin{array}{l}\text { OLIVEIRA, R. } \\
\text { D.; ALMEIDA, } \\
\text { E. C. de.; } \\
\text { TOLFO, F. T.; } \\
\text { CAREGNATTO }\end{array}$ & $\begin{array}{lr}\text { Analisar } & \mathrm{a} \\
\text { importância } & \text { da } \\
\text { liderança como fator } \\
\text { motivacional nas } \\
\text { organizações. }\end{array}$ & $\begin{array}{l}\text { Os resultados apontam a } \\
\text { importância de um líder com } \\
\text { atuação mais humanizada e que } \\
\text { dentro deste contexto consegue } \\
\text { maior motivação, maior }\end{array}$ \\
\hline
\end{tabular}




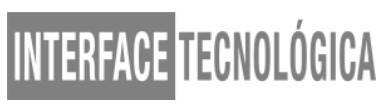

\begin{tabular}{|c|c|c|c|}
\hline Organizações & , M. I. M. & & $\begin{array}{l}\text { produtividade e satisfação de } \\
\text { seus liderados. }\end{array}$ \\
\hline $\begin{array}{l}\text { A Importância da } \\
\text { Liderança } \\
\text { Motivação nas } \\
\text { Organizações. }\end{array}$ & $\begin{array}{l}\text { CRUZ, C. A. B. } \\
\text { de. }\end{array}$ & 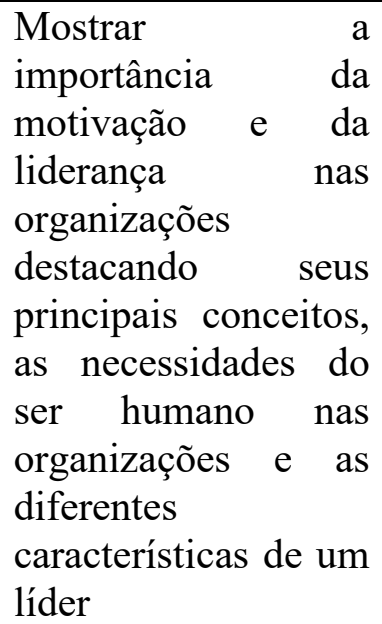 & $\begin{array}{l}\text { O líder tem papel fundamental } \\
\text { para motivar } \\
\text { colaboradores e assim } \\
\text { conseguir maior sucesso e } \\
\text { desenvolvimento para a } \\
\text { empresa }\end{array}$ \\
\hline
\end{tabular}

Fonte: Elaborado pelo autor

Segundo Chiavenato (2011) um dos papéis fundamentais dos grandes líderes é estimular as pessoas e a colaboração entres estas, desenvolvê-las, formando equipes de alto desempenho.

Cruz (2012) explica que a motivação é um fator importante para suprir as necessidades humanas, já a liderança em contrapartida surge para ajudar a desenvolver o capital intelectual dos colaboradores, enriquecendo assim o trabalho em equipe.

\section{CONSIDERAÇÕES FINAIS}

Através do presente estudo, foi possível refletir que as organizações têm evoluído juntamente com a sociedade e que sua principal busca, diferentemente do que aconteceu no passado, tem sido a satisfação de seus colaboradores.

Surge então, para fazer esse elo entre as organizações e seus colaboradores a figura do líder, cujo papel fundamental, tem sido buscar entre sua equipe, a motivação, para que haja tanto o desenvolvimento pessoal, como o desenvolvimento organizacional.

Analisando as ideias dos muitos autores acima citados, fica claro que o líder veio a somar de forma positiva ao desenvolvimento das organizações, sendo objeto influenciador das atitudes e comportamento dos colaboradores liderados por ele. Além disso, fica claro que a característica de liderança, embora muitas vezes nata, precisa ser trabalhada para que os resultados sejam os mais satisfatórios possíveis. 


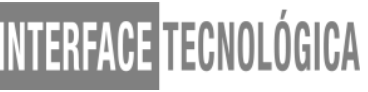

Foi possível perceber também através deste estudo, que para ser líder é preciso ter muita competência e dedicação, uma vez que o desenvolvimento das organizações muitas vezes tem crescimento proporcional ao seu trabalho realizado junto à equipe de colaboradores.

A motivação desenvolvida por meio da figura do líder, é necessária para que a organização possa contar com a maior capacidade de seus colaboradores. É dentro desse contexto que a empresa conseguirá obter o máximo da capacidade intelectual e física de seus funcionários.

Vale ressaltar que embora muitos líderes tenham a capacidade nata de liderança, muitos precisam se adaptar a essa realidade. A liderança é um processo contínuo, e precisa ser aprimorado a cada dia, sob a perspectiva de que cada ser humano é único, com personalidades e interesses diferentes. Enfim, cabe as organizações, escolher e preparar seu líder, para que o mesmo, que contribua de forma significativa para o crescimento da organização ao qual está inserido.

\section{REFERÊNCIAS}

ALVES, T. O.; ESTENDER, A. C. Liderança e sua importância para motivação organizacional. 2013. Disponível em:

http://fatece.edu.br/arquivos/arquivos\%20revistas/empreendedorismo/volume6/9.pdf. Acesso em: 20 fev. 2020.

BENNIS, W.G.; SLATER, P.L. The Temporary Society, New York: Hamper\&Row, 2002.

BOCCATO, V. R. C. Metodologia da pesquisa bibliográfica na área odontológica e o artigo científico como forma de comunicação. Rev. Odontol. Univ. Cidade São Paulo, São Paulo, v. 18, n. 3, p. 265-274, 2006.

BORGES, V. E. A Evolução do Papel do Líder nas Organizações: Um enfoque Histórico. Sumaré Revista Acadêmica Eletrônica. 2009. Disponível em: https://docplayer.com.br/51777033-A-evolucao-do-papel-do-lider-nas-organizacoes-umenfoque-historico.html. Acesso em: 2 fev. 2020. 
CHIAVENATO, I. Administração nos Novos tempos teoria, processo e prática. Rio de Janeiro: Campus, 2011.

CHIAVENATO, I. Comportamento Organizacional: a Dinâmica do Sucesso das Organizações. São Paulo: Pioneira Thomson Learning, 2006.

CONSORTI, J. C.; SCAGLIA, L. F.; CAPEL, R. R.;CILÉIA, S.A.; SILVA, M. D. Estilos de liderança: tipos de líderes da atualidade. 2011. Disponível em:

https://www.rhportal.com.br/artigos-rh/lideranca/. Acesso em: 10 mar. 2020.

CRUZ, C. A. B. de. A importância da liderança e motivação dentro das organizações. 2012. Disponível em: periodicos.set.edu.br > index.php > humanas > article > download. Acesso em: 12 fev. 2020.

DRUCKER, P. F. O líder do futuro. São Paulo: Futura, 2003.

DULUC, A. Liderança e confiança. Desenvolver o Capital Humano para as organizações competitivas. Lisboa. Piaget (2000).

HUNTER, J. C. O Monge e o executivo: Uma história sobre a essência da Liderança. Rio de Janeiro: Sextante, 2004.

MACEDO, J. F. de. Sucessão na empresa familiar: teoria e prática. São Paulo: Nobel, 2009.

MAXIMIANO, A. C. A. Teoria geral da administração: da revolução urbana à revolução digital. 6 Ed. São Paulo: Atlas, 2007.

NOGUEIRA, C. A. Administração Pública. Rio de Janeiro: Elsevier, 2005.

OHMAE, K. O novo palco da economia global: desafios e oportunidades em um mundo sem fronteiras. Tradução Werner Loeffler. Porto Alegre: Bookman, 2006.

OLIVEIRA, R. D.; ALMEIDA, E. C. de.; TOLFO, F. T.; CAREGNATTO, M. I. M. Importância da Liderança como fator Motivacional nas Organizações. 2018. XVIII Mostra de iniciação científica. Programa de Pós-Graduação em Administração. Disponível em:

http://www.ucs.br/etc/conferencias/index.php/mostraucsppga/xviiimostrappga/paper/viewFile /6029/1964. Acesso em: 2 mar. 2020. 
WUNDERLICH, M. Liderança Humanizada: o segredo da alta performance. 2017.

Disponível em: https://holos.org.br/lideranca-humanizada/. Acesso em: 12 mar. 2020. 